\title{
On Redundant Hypotheses in Inductive Fields of Inquiry
}

\author{
Rishabh Jha ${ }^{1}$, Piyush Sneh Tirkey ${ }^{2}$ \\ ${ }^{1}$ Independent Researcher, Patna, India \\ ${ }^{2}$ Department of Computer Science and Engineering, Indian Institute of Technology Kanpur, Kanpur, India
}

Email address:

rishabh.jha77@gmail.com (R. Jha), piyushsneh.sneh@gmail.com (P. S. Tirkey)

To cite this article:

Rishabh Jha, Piyush Sneh Tirkey. On Redundant Hypotheses in Inductive Fields of Inquiry. International Journal of Philosophy. Vol. 5, No. 2, 2017, pp. 12-22. doi: 10.11648/j.ijp.20170502.12

Received: March 8, 2017; Accepted: March 18, 2017; Published: April 1, 2017

\begin{abstract}
The history of human intellectual pursuit is replete with examples containing many redundant hypotheses. Here, an attempt has been made to theorize and analyze the philosophical status of redundant hypotheses along with an understanding from psychological and evolutionary perspective. The entire range of human explorations, ranging from the "God" hypothesis to the paradigm of scientific thinking has been carefully explored. A detailed assessment of redundant hypotheses and the role these play in the human psychology, is done. Further, the situation has been studied that what possibilities exist when a hypothesis becomes redundant. One such phenomenon, namely that of coincidence, has been reviewed and illustrated that how it can play a significant role in causal induction and fill the void created by scrapping off the redundant hypotheses.
\end{abstract}

Keywords: Philosophy of Redundant Hypotheses, Curiosity, The "God" Hypothesis, The "Science" Hypothesis, Coincidences, Causality, Philosophy

\section{Introduction}

The concept of hypothesis has dominated the human race in documented forms since the epoch of civilization. The inherent desire in humans to have reasons and explanations for events happening around, ranging from the rolling of a stone to the meaning of life, have led to a variety of hypotheses being proposed from time to time. The dictionary meaning [1] of 'hypothesis' is "A supposition or proposed explanation made on the basis of limited evidence as a starting point for further investigation." The same Oxford dictionary [1] also highlights the usage of the term 'hypothesis' in philosophy as "A proposition made as a basis for reasoning, without any assumption of its truth." As clear from both the definitions, 'hypothesis' itself means is a tool to explain events (whether external or internal) happening with no reference to truth. Only in the field of mathematics, it happens so that a set of axioms (another term for 'hypotheses' used by mathematicians) are assumed and the rest flows from them. Hence all deductive sciences are always circular in nature. The present work is interested in inductive fields of inquiry ${ }^{I}$. where hypotheses are assumed to explain events/reality of our universe as plausible explanations and as per the definition, those hypotheses are assumed without any assumption of truth. It is important to stress the word 'any' in the definition because it emphasizes a characteristic feature of 'hypothesis', namely its complete independence from all truth(s).

This being said, it is self-evident that hypothesis is itself a kind of assumption and being true or not depends upon the evidences obtained in its favor or against it. There are two possibilities that are exhaustive in nature. First, with gathered evidences, the hypothesis turns out to be correct. This can be made clear by an example of 'atoms'. The hypothesis of 'atoms' as one of the building blocks of universe (the other building block being the 'void' in which 'atoms' exist and move around) was first proposed by Leucippus, whose student Democritus adopted this view and further propagated and improvised the idea [2]. The ancient Greeks contributed a lot to our civilization despite of the fact that they did not

\footnotetext{
1 Based on characterization of patterns of reasoning by logicians, deductive reasoning is where conclusions must be true, if premises are true while inductive reasoning is where it is logically possible for premises to be true, yet conclusions may not be true.
} 
have sufficient tools to examine and check their ideas. Only on the basis of their gedanken experiments, they were led to such deep conclusions. It took over two thousand years to finally confirm the hypothesis of 'atoms' from whereon, this hypothesis of 'atoms' got promoted to the theory of 'atoms'.

Second possibility is that the evidences gathered refute the hypothesis. One of the most prominent examples of this is the Ptolemy's geocentric model of the universe [3] where the earth was hypothesized to be at the center of the universe, giving it a special preference and leaving lots of space for heavens to operate in the outer spheres of the universe. With the Copernican revolution, this hypothesis was refuted strongly and was thrown out of the picture once and for all.

The third possibility is the most philosophically interesting one. When the evidences gathered are neither in favor of nor against the hypothesis in question, then that makes the hypothesis redundant. In other words, the non-verification of a hypothesis makes it redundant, caving path for some other sensible hypothesis to take its place. On the face value of it, it may seem logical to not consider that hypothesis anymore because all events and evidences gathered can be explained without any need to invoke that hypothesis. But this is almost never the case. The redundant hypotheses tend to play a very dominant role in the psychology of most humans. This is so because even when found redundant, the human psychology is still dominated by the worry that redundancy does not imply being proved wrong. Hence humans have a hard time to get over a redundant hypothesis, especially those laid by some authority (that leads to orthodoxy) or some holy book, because most people do not want to take "risk" in case if the redundant hypothesis is proved right! A very illustrative example of this is the theory of Forms by Plato [4]. As per this theory, Plato states that reality exists on two level: 1 . The visible world which consists of sights and sounds. 2. The world of Forms that provides the structure to the visible world. As per this theory, anything which is in the visible world is an (imperfect) copy of the (perfect) Form that exists in the intelligible world of Forms. This means that if someone watches a rabbit, then that rabbit is a copy of the perfect rabbit that exists in the world of Forms. Since any copy is not perfect, hence this accounts for variations seen among rabbits, all such variations showing deviations from the perfect Form of rabbit. In this theory, the world of Forms cannot be seen by any mortal as it is the perfect world and hence the second hypothesis stated above is non-verifiable. Even though, if hypothesis 2 is removed, then also the mechanism of reality will not be altered, nor will any (yet to be established/found, if any exists at all) explanation of facts related to the real world. As an example, even if hypothesis 2 is not assumed at all, still rabbits will continue to exist and all of their features and behaviors will also continue to be the reality with no alteration at all, having some other explanation, if at all. Hypothesis 2, being redundant, is not required to explain truths/facts/events because of its nonverifiability, either directly or indirectly, caving the way for some other sensible explanation to take its place, if any exists at all.
In its raw (initial) form, a hypothesis (later to be found redundant) induces a dogma if laid down by any authority or some holy book. It becomes incontrovertible with time and leads to inevitable rigidness and orthodoxy. The dangers of these gradual changes in the status of (redundant) hypothesis to form a dogma can be found all around in the form of religions, supernatural beliefs etc. When such redundant hypotheses occur in the context of religions, the element of fear is provoked in humans. Sadness is more natural than happiness because fear dominates hope [5]. This happens because of the irrationality of the humans (In terms of economics, world operates more in terms of prospect theory where humans are not assumed to be rational than in terms of utility theory where humans are assumed to be rational beings). A perfectly rational person will weigh loss and profit in equal terms but this is not so for humans and thus, fear dominates hope. This sense of fear is what makes humans continue believing in redundant hypotheses (in the form of dogmas). The unfounded/unjustified reason based on the feeling of fear is because they do not want to take "risk" in case if a redundant hypothesis is proved right, then they would supposedly be condemned to eternal damnation for not believing in it!

Then the next natural inquiry arises as to what has to be done to hypotheses that are found to be redundant. The fast part of thinking [6] immediately gives the solution to stop believing in those hypotheses/dogmas but then the slow part of thinking [6] enforces the fact that every action has got consequences. A series of questions arise. Is scrapping the redundant hypotheses the only way? If not, then is it the most efficient way? If not, then using what, in which way and how, to fill the void created due to the established redundancy in the hypotheses? This paper tries to analyze the psychological origin in humans and philosophical status of redundant hypotheses, the corresponding induced dogmas and the way other (mostly underrated) factors can tend to fill the void created due to the redundancy of certain assumed hypotheses.

\section{On Psychological \& Evolutionary Origins of Redundant Hypotheses}

Humans have evolved over millions of years. Over the course of evolution, it was slowly and painfully realized that humans cannot compete with other animals when it comes to physical strength, size or speed. Hence knowingly or unknowingly, with time, the intellect of humans along with their intelligence also evolved in order to survive. All advantageous features required for survival get further advanced during the course of evolution and the remaining disadvantageous traits tend to fade away. This can be summarized in the famous phrase arising out of the Darwinian theory of evolution, i.e. "Survival of the Fittest." Humans evolved in groups, obviously. They are and have been a social species. To increase the sense of fraternity and hence to survive, the feeling of both cognitive and affective 
empathy were evolutionary developed and became a part of human reflex. To give an example, when someone watches another person fall or have an accident, this immediately generates a strong feeling of pain in the observer as if she is feeling the pain and an immediate response to help. This act of enlarged cognitive [empathy] capacity of putting oneself in others' shoes in times of pain and suffering and sympathizing with their situations is a core human trait along with improved communication abilities and the evolution of language [7], all being evolved over time and helping humans care for each other and survive.

Another fundamental trait that is of utmost significance for humans to survive all these millions of years and flourish is an immense inner crave for knowledge, or in other words, curiosity. Crave to extract and analyze information is so strong in humans and deeply embedded that sometimes humans are called "informavores" which is defined as "creatures that search for and digest information" [8]. This is a natural reflex in humans that has been developed over time because of its evolutionary advantages. Knowing the surroundings, finding suitable tools to hunt and eat, locating relevant places to sleep, etc. all helped humans survive, entirely due to the feeling of curiosity. This explains the fact that why humans did so much of explorations since prehistoric times like invention of wheel, taming of fire, inventing agriculture, creating utensils from soil to cook (a genius stroke that took over millions of years to be realized), etc. Curiosity is of utmost evolutionary importance for humans to both survive and prosper because each individual learns gradually in a lifetime that greater knowledge about the surroundings lead to primary rewards and essential resources. The fact that it is evolutionary hardwired in the brain is that a newborn human tend to look at a new visual scene for much longer in comparison to familiar visual scenes [9].

To support this claim further, it is expected that the brain should respond to new information in the same way as it responds reflexively to primary rewards like sex and food because learning is inherently rewarding. Hence, neuroimaging studies must reveal the fact that when a person's curiosity is satisfied, then there must be some kind of activation in the reward processing part of the brain. Indeed, it has been found [10] that satisfying one's curiosity (like watching a blurry picture become clear) leads to activity in dopamine neurons (residing in the midbrain) which play a fundamental role in primary reward processing.

Not only this inherent crave for knowledge got evolutionary embedded in humans but is also infectious in the sense that this feeling of curiosity, of immense inherent thirst to know, is transferable from one human to another. One of the ways among many, this infectious nature of curiosity can be illustrated as follows. Consider two humans A and B. Both have their inner crave of thirst for knowledge but they may be curious about different things. Then suppose A talks to B about her curiosity regarding some problems and also explains to $\mathrm{B}$, the proposed solution thought by A. B hears A but finds the explanation given by $\mathrm{A}$ to be poor to her own taste and reasoning. But since B is herself very curious by nature (as illustrated above), hence she starts searching for explanation that suits her reasoning and intellect and this leads to a spread of curiosity from A to B. This extremely simplistic example illustrates the fact that how curiosity is in itself communicable from one person to another in a fraternity. It also accounts for the evolution of educational systems in all human civilizations, serving the purpose to transfer the knowledge gained from one generation to another upon which the next generation can further build up using their own curiosity. This is how humans led to achieve such tremendous feats of intellectual achievements which history of humans is a testimony to.

Even though curiosity is the one of the keys to evolutionary survival, growth and prosperity, is this feeling of curiosity rational? In other words, whether the assumption or hypothesis on which this feeling of curiosity is based, namely that every event has a cause is logically justifiable or not? To answer this question, the proper question to be investigated first when it comes to knowledge is that whether or not humans are capable to know about everything? The problem with this question hinges in the word 'everything'. This is itself a very loosely defined term when it comes to inductive fields of inquiry. This can be illustrated through the theory of knowledge, namely that all of events can be divided into four categories. First those events which are known and understood, second those events which are known but not understood, third those events which are expected to exist theoretically but are still awaited to be known/found/created (in other words, events we know that we don't know yet empirically), fourth those events that are not even known that they exist or not. The fourth kind of events always poses a huge challenge because humans do not even know what they do not know. The word 'everything' is thus a very dangerous word to be used in a logical argument. Hence accordingly, the answer to the question that whether or not everything can be known or not is in negative because of the loose structure of the question. Answering this question leads to answer the previous question that the hypothesis on which the feeling of curiosity is based is not logically justifiable. Hence this evolutionary advantageous trait of curiosity in reflex of humans arises out of an unfounded faith, hence is irrational. To conclude, the underlying hypothesis of all rational explorations and intellectual achievements is itself unfounded, thus irrational.

Having concluded that the belief of everything having a reason has irrational origins, next comes the point to explore the consequences of curiosity when applied to the following three types of domains of inquiry. 1. Loosely (Vaguely) framed questions like what is life?, what is the meaning of life?, etc. 2. Questions beyond technological advancements of the day like the hypothesis of 'atoms' by Leucippus and Democritus when they did not have the technology to verify their claims. 3. Questions beyond human reach like what happened before the big bang (assuming the paradigm of the big bang happening at the starting of our universe to be true) etc. 
Human curiosity knows no limit and hence humans are hard-wired to explore anything and everything even if the domain of inquiry lies in any of the above three categories. Here comes the problem because of the limitations of verification of hypotheses assumed to explain the events belonging to the above domains of inquiry. Right from the ancient Greeks to various theories proposed in theology (some of them surveyed in the next section), various kinds of hypotheses has been proposed. Considering many of them being non-verifiable in nature, it leads inevitably to redundancy of those hypotheses because irrespective of how advanced one becomes and whatsoever how much evidences are collected, no comments can be made on the truth values of those hypotheses. Hence there arise the redundant hypotheses in the minds of "informavores".

This also explains the spread of various dogmas spread all around the world in the name of religions. Some "messiahs" tend to give "solutions" to some of the oldest sought philosophical problems by humans like definition of life, meaning of life, etc. "Informavores" crave for any sought of explanation because of the evolutionary embedded reflex feeling of curiosity. Because of this, there is a natural acceptance of the phrase "something is better than nothing" when it comes to explanations. This in turn leads to acceptance of such "solutions" as "preached" by "messiahs" (read 'supposed authorities') and this leads to elevation in status of those "solutions" (mostly redundant non-verifiable hypotheses) to dogmas. Then due to the infectious transferable nature of the feeling of curiosity among humans over generations through some form of educational systems, there comes the spread of such dogmas. Remembering the earlier discussion that such crave for explanations in humans has an irrational basis and the dominating concept of fear in human psychology [5], all these lead to a hard and fast belief in redundant hypotheses in the form of religions, supernatural elements, etc. By inverting the logic, the reasons for all such kinds of orthodoxy can be traced to (i) the irrationality of humans to believe in unfounded faith that every event has a cause and (ii) the dominant role of fear that exists in the psychology of humans.

\section{Two Case Studies}

Philosophy covers the entire range of human inquiries. It is the study of balance between religious and scientific conceptions. In terms of Bertrand Russell [15]: "The conceptions of life and the world which we call "philosophical" are a product of two factors: one, inherited religious and ethical conceptions; the other, the sort of investigation which may be called "scientific," using this word in its broadest sense. Individual philosophers have differed widely in regard to the proportions in which these two factors entered into their systems, but it is the presence of both, in some degree, that characterizes philosophy." In this section, we target both ends of philosophy for the sake of completeness, first the paradigm of science and then the "God" hypothesis, and illustrate the various dogmas and redundant hypotheses embedded in each of the both.

\subsection{The "Science" Hypothesis}

The greatest of human achievements have been made possible with the advent of scientific thinking and taking the road of rationality. A scientific hypothesis is the fundamental building block in any scientific procedures and explorations which can be supported or refuted through experiments and observations. Science has been divided into two branches: pure science which includes deductive sciences like mathematics and natural science which explains our universe and includes Physics, Chemistry etc.

The establishment of paradigm is one of the key features of any scientific revolution [11]. Every paradigm is based on some assumptions. Every new paradigm replacing the old one challenges the previous set of hypotheses and attempts to generalize the theory. The most relevant example in Physics is that of Newtonian mechanics and gravitation. Here, space and time were assumed two separate and independent entities and were hypothesized to be static in nature, playing no role at all in the dynamics of the mechanical systems like astronomical phenomena. This was one of the defining landmarks in scientific thinking and started a revolution of scientific explorations. Centuries later, Einstein, via some other way, challenged these hypotheses and came up with a much more general theory of gravitation, namely the general theory of relativity. This created a new paradigm on which generations of research is based, just like the Newtonian paradigm.

As new paradigms come in picture and a theory is generalized to more and more general scenarios, the human mind tends to think of the natural question that what will be the end point of any such inductive fields of inquiry. For example, in Physics, there is almost a universal belief to unify all fundamental forces of nature in a single combined theory. More technically speaking, there is an almost universal belief that the combination of the standard model of Physics with the theory of gravitation is possible. Such questions that arise in the minds of professionals assume two fundamental hypotheses: (i) that such an end is possible, namely unification and (ii) that indeed science is able to provide rational explanations of everything that has been found or will be found, namely the principle of causality, on which the entire paradigm of scientific thinking is based and is the most inherent feature of science. The former hypothesis rests on the optimism and is a constant source of motivation for the professionals to dedicate their intellectual energy to such pursuits. No comment can be made about the truth value of this unification hypothesis. Indeed it is feasible that such an end is possible but the subtle point is that any kind of unification in any inductive field of inquiry rests on unfounded faith and is in itself a belief. Since this belief is almost universal and is believed by the greatest of researchers (which tend to play the role of 'authorities' in the world of science), hence this belief becomes a dogma. This is not the only dogma present in science which arises due to redundancy of this hypothesis (hence can be avoided) but 
also the belief inherent in any scientific exploration that "everything" has a rational explanation (hypothesis (ii), namely causality). As any astute reader must have noticed, the problem with the latter hypothesis again hinges in the word 'everything'. As discussed above in Section 2, this is a vaguely defined term and has got an irrational basis. It is true that such beliefs are of course important to make progress and such an optimist approach is what motivates the explorer of truths. Any philosopher, who is at the same time a physicist, who knows that all such beliefs are dogmas, herself believes in them when she comes down to work as a physicist in her day-to-day life, otherwise she wouldn't expect to make progress. Also, the hypothesis (i) is logically redundant in nature because even if some physicist does not believe in having an ultimate end goal, then also she can continue to work and make progress for the sake of pursuit of truth, with no effect in results being obtained by her even if she is a non-believer (in the above sense). The hypothesis (ii) states that science can explain everything (the principle of causality) and this is so inherent in the paradigm of scientific thinking that not believing in this will lead to acute skepticism in her, making her first question the issue that whether or not a rational explanation is even possible or not, thereby making progress lethargic.

To give an example, Richard P. Feynman is one the greatest physicists of all times. He was awarded the Nobel Prize in Physics in 1965 for his fundamental contributions to quantum electrodynamics. He was once asked a question as what the end of Physics would be and what his views are on the philosophy of assumptions [12]. To which he replied that he does not know. He said (read 'warned') that one must not make any assumptions about the future description of our universe. He highlighted one of the most important points being made here in this paper that it cannot be apriori clear that whether or not our universe follows a single concise final theory. To quote him directly, he said": "People say to me, "Are you looking for the ultimate laws of physics?" No I am not. I am just looking to find out more about the world. And if it turns out there is a simple ultimate law that explains everything so be it. That would be very nice discovery. If it turns out it's like an onion with millions of layers and we just sick and tired of looking at the layers then that's the way it is! But whatever way it comes out it's nature, it's there, and she's going to come out the way she is. And therefore when we go to investigate we shouldn't pre-decide what it is we are trying to do except to find out more about it. If you said...but the problem is why we do you find out more about it, if you thought that you are trying to find out more about it because you are going to get an answer to some deep philosophical question you may be wrong and may be that you can't get an answer to that particular question by finding out more about the character of the nature."

The case of mathematics clarifies things in a crystal clear manner. Gödel's theorems [13] are the nail in the coffin for

2An extract of the $\mathrm{BBC}$ recordings can be found on: https://www.youtube.com/watch?v=MEqMM2Co_9c. any pure formal approach. They are applicable for any kind of formal (or sufficiently general) axiomatic theories. A sufficiently general axiomatic system is a system that is based on axioms and specific rules of deduction. In all consistent, sufficiently general axiomatic system, the two Gödel's theorems are [14]: (a) Gödel's Incompleteness Theorem - There always exists a proposition that cannot be deduced from the axioms. (b) Gödel's Consistency Theorem - The consistency of the axioms cannot be deduced from the axioms themselves. Both theorems point to the fact that in a certain mathematical meaning, mathematical truth cannot be always reduced to formal logic of deduction. This further implies that no formal consistent axiomatic system $\mathrm{S}$ is complete because there can always be provided some true statement(s) that cannot be formally provable in the given system S. As noted above, the ultimate victory of Physics, as assumed by most physicists, is that the whole of reality is reduced to a single theory. It must be noted that Physics is the scientific study to explain our universe but mathematics has our universe as a subset of itself. This is so because mathematics is not bounded by the reality of our universe but our universe is bounded by those set of mathematical axioms that must match with experimental results, hence making our universe a subset (or an example) of mathematics. Hence mathematics is basically a pointer to reality (our universe) and in itself is not subjected to physical laws. Any physical theory is necessarily a part of a formal system (since mathematics is being used as a pointer to explain our reality using physical theories), hence it must necessarily be incomplete.

The above illustration is very significant in countering yet another hypothesis that some physicists have in their minds while working, namely (iii) that mathematics, being viewed as the ultimate language of nature, is sufficient (or in other words, complete) to explain our entire universe. Strictly speaking, hypothesis (iii) is same as hypothesis (ii), namely causality.

This completes our discussion to highlight that the optimistic hypotheses researchers have in mind are based on unfounded faith and tend to serve as dogmas. One of them (hypothesis (i)) is redundant in nature because not believing in it will in no way change the results obtained by a researcher. For example, in a formal axiomatic system, the axioms are the only things that need to be assumed and believing or not in any extra hypotheses (that are redundant) will not change the deductive results obtained from the axioms.

But this should be made very clear that science is still a dogma without hypothesis (i) because of the hypothesis (ii) (the inherent assumption of causality in science). This hypothesis arises out of the irrationality of the human psychology, even though humans acknowledge the fact that it cannot be known apriori that whether or not the whole richness of reality can be reduced down to a formal, consistent and complete theory (which anyways is negated above in the discussions on Gödel's theorems). 


\subsection{The "God" Hypothesis}

As illustrated in Section 2, curiosity has always led humans to explore a great deal of many areas of inquiries. As pointed there, this irrational origin of curiosity has caused humans to explore even those domains where pure reason and/or the evidences fail to give satisfactory conclusions, especially when it comes to the meaning of life, what happens before birth and after death, etc. This has often led humans to various kinds of explanations that mostly belong to the realm of metaphysics. The Oxford dictionary [1] defines 'metaphysics' as "abstract theory with no basis in reality" and this is the spirit in which this is being presented here. Abstractions have often led to the conception of "God", right from the ancient Greek civilization. A wonderful and brilliant account of the history of western philosophy has been given by Bertrand Russell [15]. During the era of development of Catholicism, philosophy was driven with an end goal in mind to establish the existence of "God". As Russell correctly points out, this is never the way to proceed in any logical or philosophical analysis. True philosophy is where one starts from certain premises and land to wherever logic leads to, with no prejudices or pre-conceived notions in mind. In other words, philosophy cannot be done in a deterministic way with an end goal in sight. Hence in this way, most of the philosophies that led to the conclusions of "God" (after the great ancient Greek civilization) are in true sense, do not even qualify to be called philosophical. Here, a coherent account is presented regarding this "God" hypothesis.

There are three ways to analyze this considerably complex hypothesis. One way is to treat the "God" hypothesis as a scientific hypothesis and then scrutinize this hypothesis that leads to conclusions that are logic driven and not prejudice driven. Another way is to analyze from the standpoint of the "God" hypothesis itself. More explicitly, it is explored that within the realm of assuming the "God" hypothesis to be true, whether or not it is possible to verify the existence of "God" and if not, then whether or not this leads to any inconsistency within the domain of the "God" hypothesis itself. The third perspective to analyze the issue is that of philosophical logic. These are the three standpoints that allow one to analyze this complex situation.

The first case of treating the "God" hypothesis as a scientific hypothesis has already been greatly explored. This analysis started right since the age of Reformation and with the onset of the paradigm of science [15]. In the modern era of philosophy, science produced a considerable opposition to various dogmas of religions and "God". One of the simplistic accounts of such analysis is done by Richard Dawkins [16] in his bestseller book The God Delusion but it attempts to analyze the hypothesis very narrowly by targeting the soft spots of theology. There are various other accounts, some of them being discussed here briefly. The primary line of attack with such an approach is having some kind of experimental confirmation of "God" in a way, science finds it acceptable. The concept of intelligent design and creation on one hand and the Darwinian theory of evolution on the other have posed to be one of the greatest debates in the modern era. The various evidences collected in favor of evolution strongly support the latter, in comparison to none obtained in favor of the former, scientifically speaking. As one physicist concluded [17], "after evaluating all the evidence, we can conclude that the universe and life look exactly as they would be expected to look if there were no God".

Apart from overwhelming literature existing in this case of treating the "God" hypothesis as a scientific hypothesis, here an important subtle point is required to be noticed that clears the debate that why this hypothesis does not and will never stand the scrutiny of science. The reason lies in the philosophy of science. The way, the term 'proof' and 'science' itself have been defined in the scientific temperament [18], it is impossible for the "God" hypothesis to be proved because of its essential lack of definition. The term "God" has got no scientific definition. Since the premise is itself so vague, hence the conclusions can never hold in the favor of the premise. To make this more concrete, a specific example of philosophical analysis by G. E. Moore [19] can be used to illustrate the point. He cites three requirements that have to be satisfied by anything being termed as 'proof'. His third requirement is "that an argument must satisfy in order to qualify as a proof is that the premises must be known to be true." For premises to be known as true, first they have to be defined which is not the case here. Since premise is itself not clear, hence the entire foundation on which the rest of the analyses are based, falls down. Correspondingly it can never be 'proven' within the realm of science. To conclude this case, all analyses done to test the "God" hypothesis from a scientific standpoint are doomed to failure and are futile enough to be even attempted because of the vague meaning of the premise, the way 'proof' and 'science' itself are defined and the structure of scientific explorations [18]. Hence targeting this hypothesis from scientific point of view is never a good idea as the problem challenged is itself nonsense within the paradigm of science, making the entire analysis a waste.

But is this the only way? Of course not! Why? It is so because science cannot cover the entire spectrum of knowledge. Though science has developed more and more of a technique over time but still it is a doctrine as to the nature of reality (though it is becoming less and less but it still is so). The concept of science emerged from its practical importance in connection with war and its triumph has been due to its practical utility. The concept of "God" emerged from altogether different reasons. Hence it is incorrect to judge a doctrine using another doctrine in the spirit of philosophy. And if this attempt is taken (despite being philosophically inconsistent), then it leads to redundant (or strictly speaking, nonsensical) situations as seen in the preceding paragraph. As correctly concluded by Russell [15] that science by definition is moral-neutral and hence it is incomplete in this sense too. The philosophy of science is not only a proper philosophy in its true spirit but also "a form of madness." To quote Russell: "The philosophies that have 
been inspired by scientific technique are power philosophies, and tend to regard everything non-human as mere raw material. Ends are no longer considered; only the skillfulness of the process is valued. This also is a form of madness. It is, in our day, the most dangerous form, and the one against which a sane philosophy should provide an antidote." However, all modern and postmodern analyses of the "God" hypothesis have been done using the philosophy of science, leading to the inevitable pitfalls in conclusions as seen above. Here this pitfall has been tried to be avoided by analyzing the issue from other perspective too, making the discussion truly philosophical in nature.

Another standpoint that exists is within the realm of "God" hypothesis itself by assuming it to be true. Assuming "God" to be someone like a person is just a simplistic way to imagine the situation. One of the most beautiful accounts of various models of theology has been described by a feminist Christian theologian, Sallie McFague [20].

Within the realm of (western) theology, one of the major definitions (not in a scientific sense) or characteristic features of "God" has been that the "God" is Omnipresent, Omnipotent and Omniscient (triple O's). This position has been targeted by Anthony Kenny [21] where it is concluded that "there can be no such being as the God of traditional natural theology." Here a different perspective will be provided than that provided by Kenny.

The "God" hypothesis assumes the existence of "God" that can never be perfectly understood by humans because humans are thought to be imperfect while "God" is perfect. In a loose analogy, this hypothesis can be illustrated as follows. "God" is a kind of energy that pervades our entire universe and other universes (if they exist, which only "God" knows) as well. That energy forms the platform on which our universe (like others) exists. Hence this explains why the laws of Physics are not applicable to the "God" because Physics explains our universe but the "God" serves as the platform to our universe, thereby lying outside the scope of Physics or science in general. Further, there exist various beliefs regarding the moral-values of the "God", some like Anaximenes of Miletus believing in the material monism, while others like Heraclitus believing in the unity of opposites [15]. But whatever this internal dispute was, it is universally believed that the "God" is similar to energy that pervades 'everything' and is a basis for 'all' that exist.

Mathematics has been considered divinely in theology since ancient times due to its abstractness and its power to go beyond the senses of humans [15]. Study of mathematics has been considered to be one of the most important ways to enhance intellectuality, again because of the same reasons. Accordingly, like everything else, the undeniable beauty and truth of mathematics is then owed to the "God" $[35,36]$. Hence within the realm of the "God" hypothesis, one is led to conclude that mathematics is a part of the "God" and the "God" knows every beauty and truth that can be known (even beyond mathematics).

Keeping the above discussion in mind, next issue that arises is whether or not the existence of "God" can be 'proven' in a theological sense. If 'proved', then the entire analysis becomes internally consistent because the conclusion matches with the initial assumption of the "God" hypothesis. Otherwise, the circularity in the logic (in a deductive sense) will break down and the entire formulation will crash down. To find a way, it is important to understand how "God" comes in contact with humans, as told within the domain of theology. The following discussion assumes the existence of "personal God" that listens to and answers prayers, keeps a log of all "good" and "bad" deeds done by a mortal in order to do eternal justice, etc. This assumption is not unfounded because almost all religious doctrines believe in at least one "personal God" and provide paths to make contact.

The most important way to achieve this is through revelation. The Oxford dictionary [1] defines 'revelation' as "the divine or supernatural disclosure to humans of something relating to human existence." The term 'revelation' is used in the sense of 'divine revelation' which assures the path to connect with the "God". To give a concrete example, Part One (The Profession of Faith), Section One ("I Believe" - "We Believe"), Chapter Two (God Comes to Meet Man) of the Catechism (meaning "a summary of the principles of Christian religion in the form of questions and answers, used for religious instruction") as given on the official website of the Vatican church [22] provides routes for humans to meet the "God". Hence accordingly, it is established that however difficult it may be, but in principle it is possible to make contact.

Using logic, the above two illustrated aspects are combined, namely that of mathematics being a part of the "God" and that it being possible in principle to make contact with "God". One is led to the inevitable conclusion that indeed there exists a way to 'prove' the existence of the "God" within the realm of the "God" hypothesis itself (without ever invoking the scientific methods). The path of 'proof' is that when the "God" comes in contact with a human, they may converse about mathematics and ask through revelation, the inherent beauty and truth hidden in mathematics, available in the form of many outstanding problems in pure mathematics, like proof of Riemann hypothesis, a simpler proof of Fermat's last theorem, etc. It may not be possible to achieve contact with the "God" for an ordinary person but some priests and human authorities who preach the doctrines, must be able to do so. This provides direct 'evidence' within the scope of theology itself, both for the revelation and the "God".

Three comments are in order to clarify certain subtleties. First that the path to 'prove', as illustrated above, is one of the logical conclusions and there may exist more such paths. Second that the given way to 'prove' is inductive in nature. This means that it may be possible that one day suddenly there come an outburst of results in pure mathematics from theologians through their revelations. We are correct in concluding against the hypothesis as long as the 'proof' is unavailable but being inductive in nature, 'proof' can happen any day. So, delay is not a criterion to completely rule out the 
possibility of the "God". Third comment is basically a further clarification of the second comment, i.e. already a great amount of time has passed since the start of any established religious doctrines and no such events have happened. But who knows that thousands of years constitute "a great amount of time" or not. Perhaps "God"! But the following conclusion still holds that each day being passed with no such 'proof' happening is equivalent to an opportunity lost for theologians. That each and every day being lost is 'proving' inductively the falsification of the "God" and/or the revelation, thereby making the entire theory redundant and/or inconsistent respectively, from the standpoint of assuming the "God" hypothesis to be correct. Since the conclusions inductively point towards a contradiction, hence the assumption, from which one started, namely the assumption of the "God" hypothesis being true, is falsified. This is the standard proof by contradiction, used in pure mathematics, which itself has been considered divinely since ancient times. To finally re-emphasize the second comment due to its tremendous importance, this must be remembered at all times that all above conclusions about falsification are inductive (and not deductive) in nature.

There is yet another (third) standpoint to analyze the issue, i.e. philosophical logic, using classical ontological arguments, modern modal ontological arguments, Kurt Gödel's Ontologischer Beweis, among others. A classic text to analyze this standpoint is provided by Jordan Howard Sobel [23]. This epic analysis is beyond the scope of the present paper and is left as future work. It has been mentioned here for the sake of completeness of perspectives to analyze the current issue in question.

To end this section, it is very appropriate to point out a very relevant event from history. This is the famous Napoleon-Laplace anecdote whose one of the most typical version is provided by Rouse Ball [24]. It is: "Laplace went in state to Napoleon to present a copy of his work, and the following account of the interview is well authenticated, and so characteristic of all the parties concerned that I quote it in full. Someone had told Napoleon that the book contained no mention of the name of God; Napoleon, who was fond of putting embarrassing questions, received it with the remark, 'M. Laplace, they tell me you have written this large book on the system of the universe, and have never even mentioned its Creator.' Laplace, who, though the most supple of politicians, was as stiff as a martyr on every point of his philosophy, drew himself up and answered bluntly, Je n'avais pas besoin de cette hypothèse-là. ("I had no need of that hypothesis.") Napoleon, greatly amused, told this reply to Lagrange, who exclaimed, Ah! c'est une belle hypothèse; ça explique beaucoup de choses. ("Ah, it is a fine hypothesis; it explains many things.")"

\section{On Coincidences}

Once a hypothesis is established as redundant, then it could either be scratched off or replaced in some other ways. Scratching it off might result in the formation of a void which could prove to be ambiguous in nature. This ambiguous void may lead to further inconsistencies. So maintaining the consistency of the argument, redundant hypothesis can be replaced by something which may seem significantly underrated in the human psychology, hence often being misunderstood as irrational and escapist approach. As discussed above, it isn't necessary that everything must have a reason or a cause, since neither the idea of 'everything' is properly defined nor there exists any kind of evidence in support of the principle of causality. In spite of carrying the load of redundant hypothesis, it is better to replace it with something which makes the whole structure of hypothesis concrete and complete.

Here one approach is explored, namely the concept of 'coincidences' and the immense role this concept plays. The Oxford dictionary [1] defines 'coincidence' as "a remarkable concurrence of events or circumstances without apparent causal connection." Coincidence is an extremely misunderstood term. It is associated with several theories and explanations. The curious nature of humans always urges to seek for meaningful explanations for coincidences rather than considering it as a mere chance. The idea to be explored here is that despite of various social and psychological perceptions of the term 'coincidence', whether or not this concept is of anything significant. Hence this section provides a brief overview of the phenomenon called 'coincidence'.

Johansen and Osman [25] argue in their beautifully written paper that coincidences are a fundamental consequence of rational cognition. Apart from the standard conception about coincidences being irrational "association between the experience of coincidences and biased cognition in terms of poor probabilistic reasoning and a propensity for paranormal beliefs", a rationalist approach has been proposed for the psychology of coincidence. It has been termed as $3 C$ 's model: "1. (C)oincidence detection; 2. (C)ausal mechanism search; 3. (C)oincidence versus cause judgment." The paper concludes with experience of coincidences being "a necessary consequence of rational causal learning mechanisms and provides a widely ignored approach to evaluating the mechanisms of causal reasoning." The three key findings on coincidences are biased judgments, paranormal beliefs and individual differences not being reliable predictors of the frequency with which coincidences are experienced. This analysis leads to the inevitable conclusion that coincidences and causality are the two different sides of the same coin, thereby providing coincidences as "an extremely useful alternative perspective on the mechanisms of causal induction ["learning about the existence of a relationship between a single cause and effect, based upon causal graphical models" [38]]." There are two categories, one being the irrational assumption of causality (as discussed above) providing inductive justification about "coincident" activities to be repeated in future (known as projectable) while those that are nonprojectable [26]. The latter case is of immense importance because ascribing coincidences to chance leads to coincidences being nonprojectable concepts. 
Other routes researchers take to explain coincidences are using the idea of events associated with low probability of occurring [27]. A major part of the human belief system is molded by the way they experience coincidences. In majority of the cases, since people are unable to understand and conceive coincidences, they ultimately fall into the trap of believing magic, superstitions, conspiracy theory, existence of the super being ("God"), etc. These phenomena of experiencing coincidences and then falling into the trap of superstitious beliefs are widespread [28]. Further it is also defined emphasizing connected mental states that reject the idea of causality for the coincidences. Quoting one of the definitions [29], "A coincidence experience may be defined as the occurrence of two (or more) odd, surprising, out-ofthe-ordinary or personally meaningful events connected in the mind of the observer". Researchers having this belief mostly try to analyze people's reported experience of coincidences and then further define coincidence based on this [37]. Linking coincidence with causality has been one of the major approaches by researchers. Quoting Griffiths and Tenenbaum [30]: "Coincidences arise when there is a conflict between the evidence an event provides for a theory and our prior beliefs about the plausibility of that theory. More precisely, a coincidence is an event that provides support for an alternative [possibly paranormal] to a current theory, but not enough support to convince us to accept that alternative."

Collectively including all the perspectives, 'coincidences' could be defined as "coincidences are surprising pattern repetitions ["anomalies" [31]] that are observed to be unlikely by chance but are nonetheless ascribed to chance since the search for causal mechanisms has not produced anything more plausible than mere chance" [25]. This could also be understood with the help of the " 3 C's Framework for Coincidences." This understanding of coincidences under the $3 \mathrm{C}$ 's framework indeed is one way to fill the void which is created upon removal of redundant hypotheses, coincidences being a beneficial perspective on the mechanism of the causal induction.

Carl Jung's concept of synchronicity [32] is a major landmark in the study of coincidences. He argued in his book that events may be connected either by causality or by meaning. Hence even if there does not exist any causal relationships, then too there can be meaningful coincidences. This leads to the conclusion that standard science, causality, physics, statistics, and probability (for instance, Littlewood's law or the law of truly large numbers) may or may not explain synchronistic events and such events may exist (example: mathematical coincidence). One of the critics [33] stated that "This danger is the temptation to mental laziness. [...] it would be very tempting to say, "Well, it's synchronistic, it's forever beyond my understanding," and so (prematurely) give up trying to find a causal explanation." Popular phrases have led from his theory like "there are no coincidences' and 'everything happens for a reason.' The only problem with such phrases/understanding is that there are no evidences to show that this is true. As argued in this paper, this again stems from the irrational belief of humans that an event can either be explained in terms of causality or meaning, both ways having no evidence at all to support them. Hence the concept of 'coincidence' being discussed here is much more general than the narrow analysis done by Jung.

But this is for certain that not all coincidences can be ascribed to chance because scientific achievements rely heavily on explaining the initially supposed coincidences. So, the next natural question is: what is not a coincidence? For an event to be considered as a coincidence, it is necessary for it to be rare, but not the other way [30]. For example, rolling twenty dice on a board will produce a particular set of numbers with each dice showing a particular integer between 0 and 7, but this particular set won't be considered to be a coincidence until there is an event like all twenty dice showing the same number. Similarly, another instance, that of Halley's discovery [34], is an example of causal induction where he inferred causal structure from the coincidences in the data. So, to conclude the section, coincidences are another perspective on causal induction, both being different sides of the same coin and vastly divergent conceptually, with a precaution in mind to distinguish whether an event is coincident or not.

\section{Conclusion}

The conclusion of the paper can be metaphorically summed up by the following quotation by Douglas Adams [39], "Isn't it enough to see that a garden is beautiful without having to believe that there are fairies at the bottom of it too?" In this paper, it has been illustrated that the concept of hypothesis pervades any kind of human explorations. This is so because in order to explain any phenomenon, a model is required which itself is based on various assumptions. The need of hypotheses becomes inevitable in any kind of model that is used to explain actual phenomena. Newton's three laws of motion constitute a great example to illustrate this point of model building. The first law lays the platform on which the next two laws hold. First law clearly states to imagine a hypothetical universe where in an inertial frame, a body continues to be in a state of motion or rest unless acted upon by an external force. Then the second law provides for a definition of force and a way to calculate it, in that hypothetical universe only that has been laid down in the first law. Similarly, the third law also holds in that universe only. Hence, Newton's laws try to explain our mechanical classical universe by building a hypothetical universe where these laws hold and this model itself is based on assumptions like absolute (passive) behavior of space and time among others.

The philosophical status of hypotheses has been explored here. It has been shown that a hypothesis becomes redundant when it cannot be proved or refuted by any means possible and yet continues to be a part of the model built for some kind of explanations. This leads to the obvious dilemma that why then such redundant hypotheses continue to play such major roles in any civilization as well as in human psychology. To answer this question, the psychological origin 
has been explored here. Human curiosity turns out to be a fundamental instinct that plays a very dominant and evolutionary advantageous role. Supported by evolutionary perspective, another property of human curiosity has been illustrated, namely its contagious nature and an explanation for the emergence of education system in any human civilization has also been provided. After such evolutionary and psychological benefits, it has been showed that the origin of curiosity does not have a rational basis because no evidence or arguments support the belief in causality. This irrational belief in causality and the immense thirst for reasons lead to belief in any kind of hypothesis (even if redundant) simply in order to satisfy the inner intellectual thirst. It has been found that the reasons for all kinds of orthodoxy can be traced to (i) the irrationality of humans to believe in unfounded faith that every event has a cause and (ii) the dominant role of fear that exists in the psychology of humans.

Finally to make all investigations concrete, two case studies has been studied in this paper, covering the two ends of philosophy, one being religious and ethical conceptions, the other being the scientific explorations. The "science" hypothesis rests on two beliefs: (i) that an end or some kind of unification of vastly different explorations is possible and (ii) the principle of causality. The former is a redundant hypothesis along with an irrational belief and the latter, an irrational belief. The latter, in a strict sense, is also a redundant hypothesis, given that its removal does not induce any kind of lethargy in ongoing researches. They induce a kind of dogma and as Russell [15] pointed out correctly that any philosophy inspired solely by scientific philosophies is also "a form of madness."

The "God" hypothesis has been explored next and three different perspectives exist: (i) treating this hypothesis as a scientific hypothesis, (ii) analyzing within the realm of theology itself assuming this hypothesis to be true and (iii) philosophical logic. The first of these standpoints is shown to be trivial because targeting the "God" hypothesis from scientific point of view leads to inevitable logical pitfalls as the problem/hypothesis challenged is itself nonsense within the paradigm of science, making the entire analysis a waste. The second perspective leads to a way that can 'prove' "God" within the realm of theology. This also leads to the fact that since such 'proofs' have not been achieved till date, hence leading to falsification of the "God" hypothesis inductively. The third perspective is beyond the scope of this paper and is left as a future work.

Finally the paper deals with the possibilities that arise when any redundant hypothesis is scratched off. One of the most relevant phenomena, namely coincidence, has been briefly reviewed. The entire issue boils down to the problem of coincident phenomena and the nature of mechanism of causal induction. They are found to be different sides of the same coin. A wide range of literature has been surveyed, ranging from Jung's concept of synchronicity to $3 \mathrm{C}$ 's framework for coincidences.

As an afterthought, it can be said that the reason why hypotheses play such a fundamental role in day-to-day lives is because every person makes some model of the world around. It does not matter how the world is in reality but actually how one perceives it is what creates all difference and accounts for such large variations in human thoughts and nature. This perception dependent reality is the root cause of hypotheses (including redundant ones) playing such deep role in everyday life. This paper is an attempt to properly theorize and systematically study the consequences of redundant hypotheses from a philosophical point of view. This concept is undoubtedly linked to the philosophy and psychology of coincidences that has been briefly surveyed in this paper. Further, fundamental analyses can be done on the mechanism of causal induction, redundant hypotheses and phenomena of coincidences, tying them altogether, revealing deep insights about human psychology, perception and evolutionary advantages. This will help "unify" the three pillars of understanding the reality: philosophy, psychology and science, in a golden braid, supported by evidences to be found in the Darwinian school of evolution and neuroscience among others.

\section{References}

[1] The English Oxford Living Dictionaries (Online). https://en.oxforddictionaries.com/.

[2] The Editors of Encyclopædia Britannica. Democritus in Encyclopædia Britannica, Inc., 2015. https://www.britannica.com/biography/Democritus.

[3] Alexander Raymond Jones. Ptolemaic System in Encyclopædia Britannica, Inc., 2003. https://www.britannica.com/topic/Ptolemaic-system.

[4] Paul Kleinman. Philosophy 101: From Plato and Socrates to Ethics and Metaphysics, an Essential Primer on the History of Thought (Adams 101). Fw Media, 2013.

[5] Rishabh Jha. On Origins of Sadness and Happiness in The International Journal of Humanities \& Social Studies (THEIJHSS - ISSN: 2321-9203), Volume 4, Issue 7, July 2016, pp. 147-155.

[6] Daniel Kahneman. Thinking, Fast and Slow. Farrar, Straus and Giroux; Reprint edition, 2013.

[7] C. S. Carter, J. Harris, S. W. Porges. Neural and Evolutionary Perspectives on Empathy (Chapter 13) in The Social Neuroscience of Empathy, edited by Jean Decety, William Ickes. The MIT Press, 2011, pp. 169-182.

[8] G. A. Miller. Informavores in The Study of Information: Interdisciplinary Messages, edited by F. Machlup, U. Mansfield. New York, NY: Wiley, 1983, pp. 111-113.

[9] S. Friedman, A. N. Nagy, G. C. Carpenter. Newborn attention: differential response decrement to visual stimuli in Journal of Experimental Child Psychology, Volume 10, Issue 1, 1970, pp. 44-51.

[10] E. S. Bromberg-Martin, O. Hikosaka. Midbrain dopamine neurons signal preference for advance information about upcoming rewards in Neuron, Volume 63, Issue 1, 2009, pp. 119-126. 
[11] Thomas S. Kuhn. The Structure of Scientific Revolutions. University of Chicago Press; New Edition of $3^{\text {rd }}$ Revised Edition, 1996.

[12] Richard P. Feynman. The Pleasure of Finding Things Out: The Best Short Works of Richard P. Feynman. Perseus Books, 1999.

[13] K. Gödel. Über formal unentscheidbare Sätze der Principia Mathematica und verwandter Systeme I in Monatshefte für Mathematik und Physik, Volume 38, Issue 1, 1931, pp. 173198.

[14] Alfred Driessen. Philosophical consequences of the Gödel theorem in Human Approaches to the Universe. LutherAgricola-Society, edited by Eeva Martikainen, 2005.

[15] Bertrand Russell. A History of Western Philosophy. Simon \& Schuster/Touchstone, 1967.

[16] Richard Dawkins. The God Delusion. Mariner Books, US; Reprint edition, 2008.

[17] Victor Stenger. The God Hypothesis in "God issue" of New Scientist, March 17, 2012.

[18] Merrilee H. Salmon (Author, Editor), et al. (Author), John Earman (Editor), Clark Glymour (Editor), James Lennox (Editor). Chapters 1-3 in Introduction to the Philosophy of Science. Hackett Publishing Co, Inc., 1999.

[19] Scott Soames. Chapter 2 in Philosophical Analysis in the Twentieth Century, Volume 1: The Dawn of Analysis. Princeton University Press; Revised Edition, 2005, pp. 18-21.

[20] Sallie McFague. Metaphorical Theology: Models of God in Religious Language. Augsburg Fortress; $1^{\text {st }}$ edition, 1959.

[21] Anthony Kenny. The God of the Philosophers. Oxford University Press, 1986.

[22] http://www.vatican.va/archive/ccc_css/archive/catechism/p1s1 c2a1.htm.

[23] Jordan Howard Sobel. Logic and Theism: Arguments For and Against Beliefs in God. Cambridge University Press; $1^{\text {st }}$ edition, 2009.

[24] W. W. Rouse Ball. A. Short Account of the History of Mathematics. Dover Publications Inc.; $4^{\text {th }}$ Revised edition, 2003.

[25] Mark K. Johansen, Magda Osman. Coincidences: a fundamental consequence of rational cognition in New Ideas in Psychology, Volume 39, 2015, pp. 34-44.
[26] Nelson Goodman. Fact, Fiction, and Forecast. Harvard University Press; $4^{\text {th }}$ edition, 1983.

[27] John Venn. The Logic of Chance: an Essay on the Foundations and Province of the Theory of Probability, with Essential Reference to its Logical Bearings and its Application to Moral and Social Science, and to Statistics. MacMillan \& Company; $3^{\text {rd }}$ Edition, 1888.

[28] Richard Wiseman. UK Superstition Survey. Psychology Department, University of Hertfordshire. 2003. http://www.richardwiseman.com/resources/superstition_report .pdf.

[29] J. Henry. Coincidence Experience Survey in Journal of the Society for Psychical Research, Volume 59, 1993, pp. 97.

[30] T. L. Griffiths, J. B. Tenenbaum. From Mere Coincidences to Meaningful Discoveries in Cognition, Volume 103, Issue 2, 2007, pp. 180-226.

[31] Josef Kittler, William Christmas, Teófilo de Campos, David Windridge, Fei Yan, John Illingworth, Magda Osman. Domain Anomaly Detection in Machine Perception: A System Architecture and Taxonomy in IEEE Transactions on Pattern Analysis and Machine Intelligence, Volume 36, Issue 5, 2014, pp. 845-859.

[32] Carl Jung. Synchronicity: An Acausal Connecting Principle. Routledge; $1^{\text {st }}$ Edition, 2013.

[33] Charles T. Tart. Causality and synchronicity: Steps toward clarification in Journal of the American Society for Psychical Research, Volume 75, Issue 2, 1981, pp. 121-141.

[34] T. L. Griffiths, J. B. Tenenbaum. Theory-Based Causal Induction in Psychol Rev., Volume 116, Issue 4, 2009, pp. 661-716.

[35] Vem Poythress. A. Biblical View of Mathematics in Foundations of Christian Scholarship, edited by Gary North. Ross House Books: Vallecito, CA, 1976.

[36] J. C. Keister. Math and the Bible in The Trinity Review, No.: 27, 1992.

[37] P. Diaconis, F. Mosteller. Methods for studying coincidences in Journal of the American Statistical Association, Volume 84, No. 408,1989 , pp. 853-861.

[38] T. L. Griffiths, J. B. Tenenbaum. Structure and Strength in Causal Induction in Cognitive Psychology, Volume 51, 2005, pp. 334.

[39] Douglas Adams. The Ultimate Hitchhiker's Guide to the Galaxy. Del Rey, 2002. 